\title{
Design and Study of an mmWave Wearable Textile Based Compact Antenna for Healthcare Applications
}

\author{
Mohammad Monirujjaman Khan $\mathbb{D}^{1},{ }^{1}$ Junayed Hossain,, ${ }^{1}$ Kaisarul Islam $\mathbb{D}^{1}$, \\ Nazmus Sadat Ovi, ${ }^{1}$ Md. Nakib Alalm Shovon, ${ }^{1}$ Muhammad Inam Abbasi $\mathbb{D},{ }^{2}$ \\ and Sami Bourouis (iD $^{3}$ \\ ${ }^{1}$ Department of Electrical and Computer Engineering, North South University Bangladesh, Bashundhara, \\ Dhaka 1229, Bangladesh \\ ${ }^{2}$ Centre for Telecommunication Research \& Innovation (CETRI), \\ Faculty of Electrical and Electronic Engineering Technology (FTKEE), Universiti Teknikal Malaysia Melaka (UTeM), \\ Melaka 76100, Malaysia \\ ${ }^{3}$ Department of Information Technology, College of Computers and Information Technology, Taif University, P.O. Box 11099, \\ Taif 21944, Saudi Arabia
}

Correspondence should be addressed to Mohammad Monirujjaman Khan; monirujjaman.khan@northsouth.edu

Received 12 November 2021; Accepted 9 December 2021; Published 20 December 2021

Academic Editor: Eng Hock Lim

Copyright (C) 2021 Mohammad Monirujjaman Khan et al. This is an open access article distributed under the Creative Commons Attribution License, which permits unrestricted use, distribution, and reproduction in any medium, provided the original work is properly cited.

\begin{abstract}
In this study, the design of a compact and novel millimeter wave cotton textile-based wearable antenna for body-centric communications in healthcare applications is presented. The free space and on-body antenna performance parameters for the proposed antenna at $60 \mathrm{GHz}$ are investigated and analyzed. The antenna is based on a $1.5 \mathrm{~mm}$ thick cotton substrate and has an overall dimension of $7.0 \times 4.5 \times 1.5 \mathrm{~mm}^{3}$. In free space, the antenna is resonant at $60 \mathrm{GHz}$ and achieves a wide impedance bandwidth. The maximum gain at this resonant frequency is $6.74 \mathrm{dBi}$, and the radiation efficiency is $93.30 \%$. Parametric changes were carried out to study the changes in the resonant frequency, gain, and radiation efficiency. For body-centric communications, the antenna was simulated at 5 different distances from a three-layer human torso-equivalent phantom. The radiation efficiency dropped by $24 \%$ and gradually increased with the gap distance. The antenna design was also analyzed by using 10 different textile substrates for both free space and on-body scenarios. The major benefits of the antenna are discussed as follows. Compared to a previous work, the antenna is very efficient, compact, and has a wide bandwidth. In BCWCs for e-health applications, the antenna needs to be very compact due to the longer battery life, and it has to have a wide bandwidth for high data rate communication. Since the antenna will be wearable with a sensor system, the shape of the antenna needs to be planar, and it is better to design the antenna on a textile substrate for integration into clothes. The antenna also needs to show high gain and efficiency for powerefficient communication. This proposed antenna meets all these criteria, and hence, it will be a good candidate for BCWCs in e-health applications.
\end{abstract}

\section{Introduction}

The advancement of wireless technology has led to an increased use of body-centric wireless communication over the years. Wireless body area networks (WBANs) are networks of wireless devices that work in the vicinity of the human body. These devices or sensors can be located around the body or implanted inside. WBANs have been widely used in many areas of life, which include healthcare, entertainment, identification systems, sports, and military. Miniaturization of hardware and embedded systems enabled the development of wearable devices. Brands such as Apple, Nike, and Adidas are providing smart watches and clothes that are being used for tracking and collecting vital biomedical data. Electronic health (e-health) is a new and attractive research area. With the help of ICT (information 
communication technology), innovative technologies are becoming a blessing for us. E-health is a technology that establishes a bridge between remote patients and specialized city doctors. Nowadays, patients with chronic diseases are on the rise. Many people in the whole world are suffering from chronic obstructive pulmonary disease (COPD), hypertension, asthma, diabetes, heart disease, and other chronic diseases. Continuous monitoring and treatment planning of these patients is very essential. E-health will play a vital role in the continuous monitoring of the vital physiological parameters (electrocardiogram (ECG), oxygen saturation (Spo2), pulse rate, temperature, blood glucose level, blood pressure, electrocardiogram (EEG), and others) of chronic patients. In this case, for body-centric communications in e-health application scenarios, many sensors integrated with antennas and systems will be around the human body to measure the vital physiological signs of the human body, and this measured data will be sent to remote doctors or hospitals or healthcare caregivers or healthcare service providers for continuous patient monitoring and treatment planning [1-10]. A tiny and efficient wearable antenna plays a vital role in body-centric communications in e-health applications. The antenna establishes communication between the on-body sensor systems and the body-worn base unit. The antenna also establishes communication from on-body devices to off-body units. Antennas designed for wearable devices need to be lightweight, flexible, and small. Textile antennas are suitable for wearable applications as they can be directly integrated into clothes, shoes, and watch straps. These antennas can be fabricated from commercially available textiles such as cotton, denim, and polyester, which offer a fairly large surface area and are perfect for use as the antenna substrate [7,9-11]. The radiating elements and the ground plane can be designed from a special type of conducting fabric known as electrotextile. Electrotextiles provide flexibility and robustness and can withstand extreme conditions such as washing and high temperatures. The different manufacturing processes of electrotextiles have been reviewed in detail in $[5,8,11]$.

Antennas designed for body-centric applications are subject to various lossy environments, and performance degradation is expected. Textile antennas are porous and can hold water, which leads to a change in density and thus electrical properties. In addition, rough surfaces, different manufacturing methods, bending, and crumpling conditions can further affect the overall performance of the antenna [7]. The human body can absorb radiated power, and antennas close to it will experience radiation pattern distortion, a shift in resonant frequency, and input impedance changes $[1,6,12-14]$. A dual-band textile antenna for the industrial, scientific, and medical (ISM) band has been studied [6]. The antenna is based on a denim substrate, and under human body conditions, the resonant frequencies slightly shift to the left. An ultrawideband (UWB) wearable antenna based on a denim substrate has been proposed [7]. A wearable textile antenna for microwave imaging has been proposed [14]. The antenna integrates copper taffeta, an electrotextile, onto a $0.5 \mathrm{~mm}$ thick polyester fabric. The antenna was placed on a human phantom, which replicates the dielectric properties of tissue containing skin, fat, and muscle. The antenna was studied by maintaining a certain amount of air in a gap between the antenna and the phantom. A similar analysis has been done in [15] for an antenna based on a denim substrate. In [8], a UWB wearable antenna based on flannel fabric has been studied for wet and bending conditions.

Current wireless communication systems are mainly based on the $2.45 \mathrm{GHz}$ band or the UWB spectrum. With an increased number of wireless networks, these systems are getting more congested. Future systems will be based on much higher frequency bands in the millimeter wave (mmWave) range. The $60 \mathrm{GHz}$ band is an unlicensed mmWave band with an available bandwidth ranging from 7 to $9 \mathrm{GHz}$ around the world. For short-range high data rate transmission, the $60 \mathrm{GHz}$ band provides the perfect solution as its UWB counterparts can only provide speeds of less than $1 \mathrm{Gbps}$ at distances of up to $10 \mathrm{~m}$. The data rate can reach speeds of up to $7 \mathrm{Gbps}$. The path loss at $60 \mathrm{GHz}$ is quite high, and the wave propagation is further attenuated by atmospheric absorption. At $60 \mathrm{GHz}$, the waves are resonant with oxygen molecules, which results in high attenuation. This feature has been observed as an advantage as communication in this band cannot be interfered with by adjacent WBANs. This makes the $60 \mathrm{GHz}$ band very secure, and until recently, it has been primarily used in noncommercial applications such as military and satellite communications. The shadowing effect can cause difficulties for nonline of sight (NLOS) communication, and so, only line of sight (LOS) channels are considered. By taking several factors into account, such as distance, power constraint, bandwidth, high attenuation, and link budget analysis, it has been shown that antennas designed for this band require high gain. Typically, $9 \mathrm{dBi}$ is considered a medium-gain antenna. A $17.92 \mathrm{dBi}$ gain, E-shaped array antenna has been investigated for the $60 \mathrm{GHz}$ band [16]. In [4], two high-gain antennas, a printed Yagi array, and a substrate integrated waveguide (SIW) Yagi have been proposed for body-centric communications. The printed Yagi achieved a gain of $17 \mathrm{~dB}$ and a $6 \mathrm{GHz}$ impedance bandwidth, whereas the SIW Yagi achieved a gain of $15 \mathrm{~dB}$ with an impedance bandwidth of just over $1 \mathrm{GHz}$.

At $60 \mathrm{GHz}$, the human body is electrically very large. As a result, body sections can be approximated by regular geometrical shapes. For example, a torso can be modeled by a flat rectangular phantom or a section of a hand can be modeled by a multilayer cylinder $[2,13]$. In $[17,18]$, a threelayer torso-equivalent phantom was created for investigating different design variations of a novel $60 \mathrm{GHz}$ antenna. These antennas maintained good radiation efficiency and gain in both free space and body-centric scenarios. The human skin absorbs $90 \%$ of the energy at $60 \mathrm{GHz}$, and the average penetration depth is only $0.5 \mathrm{~mm}$ [1-3]. As a result, the majority of reported body-centric $60 \mathrm{GHz}$ antennas are evaluated on a skin-equivalent phantom rather than a threelayer model $[2,3,12]$. Textile antennas designed for the $60 \mathrm{GHz}$ band are rare, and only a handful of such antennas have been reported in the known literature. The effect of cotton and felt textiles on propagation along the body at $60 \mathrm{GHz}$ is presented in [19]. These textiles were placed on a 
flat skin model for evaluation. Similar analysis has been carried out using electrotextiles [20] for potential use in the $60 \mathrm{GHz}$ band. A four element microstrip patch antenna array attached to a piece of cotton fabric is studied in terms of reflection coefficient, radiation pattern, and efficiency [9]. The antenna is fed by a $15.2 \mathrm{~mm}$ long microstrip line, and in free space, the antenna is well matched in the 57-64 range. The antenna has a maximum gain of $8.6 \mathrm{dBi}$ with an efficiency of $41 \%$. The antenna was simulated on a $2 \times 100 \times 100 \mathrm{~mm}^{3}$ skin-equivalent phantom. The end-fire radiation pattern achieved by the antenna is suitable for onbody applications. The antenna's return loss and gain largely remained stable under on-body measurements. To improve the gain and efficiency, it was suggested that the feed line be shortened. A similar substrate has been used in [10] for designing a Yagi-Uda antenna for wearable applications. These antennas were investigated for body-centric communications on a skin-equivalent phantom. The antenna was mounted on a $10 \times 100 \times 100 \mathrm{~mm}^{3}$ skin-equivalent phantom. A compact, novel-shaped textile antenna based on a polyester substrate has been proposed in [21]. The antenna was also simulated using 10 different textile substrates in free space and body-centric setups. In free space, the antenna was $89.4 \%$ efficient and achieved an impedance bandwidth of 11.6 GHz. A printed Q-slot millimeter wave $60 \mathrm{GHz}$ antenna is proposed for BCWCs [22]. The antenna was printed on an FR-4 substrate, and it shows wide bandwidth and has a radiation efficiency of $82.15 \%$.

The objective of this research is to design a tiny and novel mmWave cotton textile-based antenna for body-centric communications in healthcare applications. The major contributions of this research are that we present a design for a very compact, novel $60 \mathrm{GHz}$ microstrip patch antenna based on a cotton substrate for BCWCs for healthcare applications. The antenna has a very wide bandwidth, and it has good gain and very high efficiency. Similar to the work presented in $[17,18,21]$, this antenna design will be simulated in free space and on a three-layer torso phantom using CST Microwave Studio. The antenna will also be simulated using 10 different textile substrates as presented in [21]. The antenna is found to be the lowest-sized textilebased mmWave antenna that works at $60 \mathrm{GHz}$ with very wide bandwidth and high efficiency. Hence, this antenna is a novel design at $60 \mathrm{GHz}$ for body-centric wireless communications in healthcare applications.

This study consists of seven different sections. The antenna design is presented in Section 2. The free space simulation results along with parametric studies are given in Section 3. In Section 4, body-centric simulations are presented. Various textile substrate simulation results are presented in Section 5. The proposed design is compared to other reported designs and is detailed in Section 6. In the last section, a conclusion is drawn.

\section{Antenna Design}

WBAN antennas need to operate in any of the following three available modes: in-body, on-body, and off-body. The first mode is used for implanted devices that need to communicate with other nodes outside the human body. The implanted devices could be medical sensors for collecting vital information from inside the body. On-body devices are placed just outside the body and are connected to a network. Off-body communication is when an on-body device wirelessly communicates with another device away from the human body. Antennas should be designed to minimize the effects on the human body. Each antenna type, such as planar inverted $\mathrm{F}$ antenna (PIFA), patch, and dipole, shows different radiation patterns. For on-body propagation, an end-fire radiation pattern is required for on-body propagation, and for off-body propagation, broadside radiation is required [8]. Yagi-Uda antennas provide a radiation pattern useful for on-body propagation. Microstrip patch antennas are small and compact in size, lightweight, and have a planar structure that is suitable for wearable devices. Additionally, low cost and ease of fabrication make patch antennas an attractive prospect. Patch antennas produce broadside radiation, which is desirable for off-body communication.

The proposed textile patch antenna design consists of three planar structures. The main radiating patch has a novel shape made by combining a semiellipse and a parallelogram. These shapes are highlighted in Figure 1(a). The semiellipse has a height of $1.35 \mathrm{~mm}$ and a radius of $0.95 \mathrm{~mm}$. The detailed dimensions of the parallelogram (the top portion of the semiellipse) are shown in Figure 2, and the values are given in Table 1 . The antenna is fed by a $2.98 \mathrm{~mm}$ long, $0.65 \mathrm{~mm}$ wide microstrip feed line, which is attached to the semiellipse. The radiating structure is placed on top of a $1.5 \mathrm{~mm}$ thick cotton substrate with a relative permittivity of 1.63. Patch antennas usually provide low gain and narrow bandwidth. The wavelength of this antenna at $60 \mathrm{GHz}$ is $5 \mathrm{~mm}$. Textile substrates such as cotton have low relative permittivity, which lowers the surface wave losses and, in turn, increases the spatial waves and thus the impedance bandwidth $[5,16]$. The ground plane, which is attached to the bottom of the substrate, has slots that cover the radiating patch on the opposite side for matching and improving the bandwidth. Figure 1(b) shows the shapes of the slots that have been removed from the ground plane. Slicing the portion of the ground neutralizes the inductive load of the patch to produce a purely resistive load, which improves the impedance bandwidth [8]. The presence of a ground plane can minimize back radiation to the human body [12]. An absence in the ground plane will increase exposure and local temperature and can also shift the resonant frequency for body-centric communications [2].

Electrotextiles are typically used in microwaves for radiating elements and in the ground plane to achieve high flexibility. At millimeter waves, fabricating antennas using electrotextiles are very complicated due to the size and geometrical dimensions of mmWave antennas. Inaccuracies in the cutting process will affect the performance of the antenna. Thus, a perfect electric conductor (PEC) of a thickness of $0.035 \mathrm{~mm}$ has been used for the radiating elements and the ground plane. The overall dimension of the antenna is $7.0 \times 4.5 \times 1.5 \mathrm{~mm}^{3}$. Table 2 provides all the different materials used in designing the antenna. At the frequency of operation of $60 \mathrm{GHz}$, the electrical size of the 


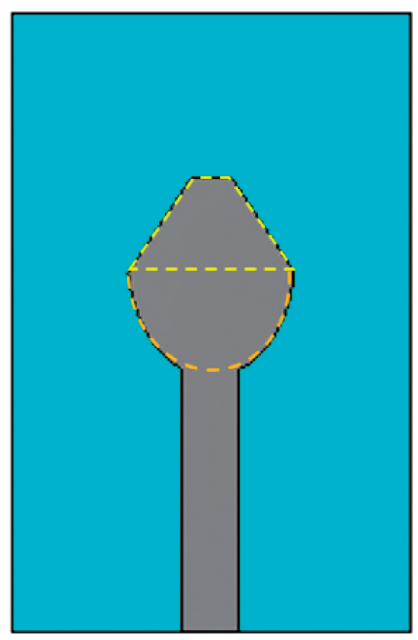

(a)

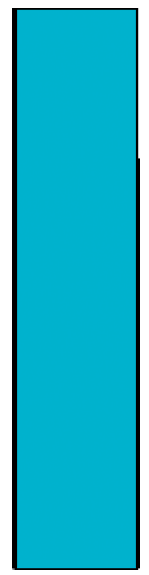

(d)

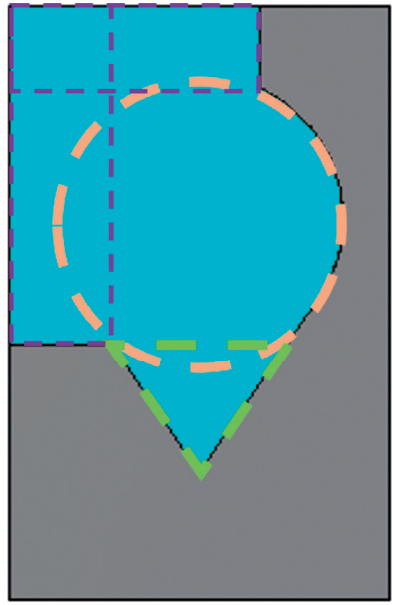

(b)

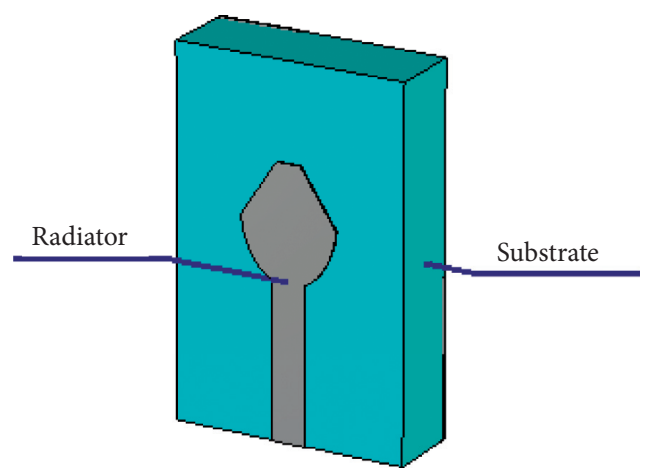

(e)

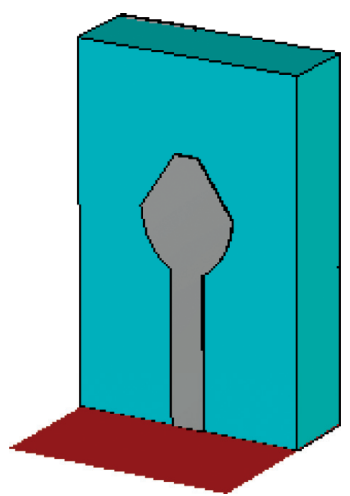

(g)

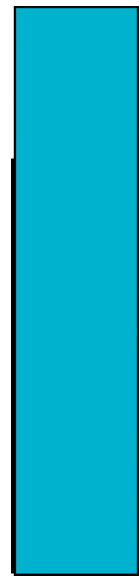

(c)

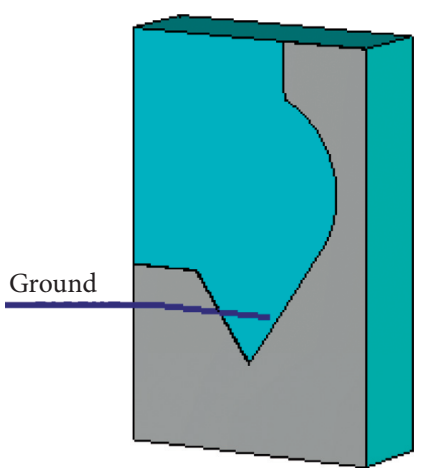

(f)

Figure 1: Different antenna views. (a) Front view. (b) Back view. (c) Right view. (d) Left view. (e) Perspective front view. (f) Perspective back view. (g) Perspective front view with port.

antenna over the overall substrate length, width, and height is $0.714 \lambda, 1.25 \lambda$, and $3.33 \lambda$, respectively. Figures $1(\mathrm{a})-1(\mathrm{~g})$ show the different views of the antenna. The different parts and the detailed dimensions of the antenna are given in Table 1 and shown in Figures 2(a)-2(d). The electrical size of the antenna at the centre frequency of $60 \mathrm{GHz}$ in terms of length and width of the radiating element of the antenna is 1.90 and 1.47 .

\section{Free Space Simulation Results}

Free space simulations were run from 40 to $80 \mathrm{GHz}$, and the results indicate that the antenna is well matched in this frequency range. The antenna is resonant at $60 \mathrm{GHz}$ with a return loss magnitude of $-21.2 \mathrm{~dB}$ and has a $-10 \mathrm{~dB}$ impedance bandwidth of more than $40 \mathrm{GHz}$ (Figure 3(a)). The voltage standing wave ratio (VSWR) is less than the desired 


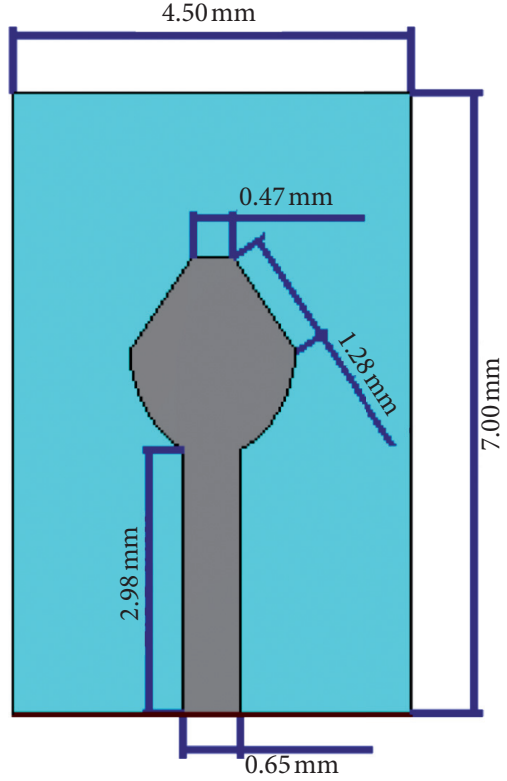

(a)

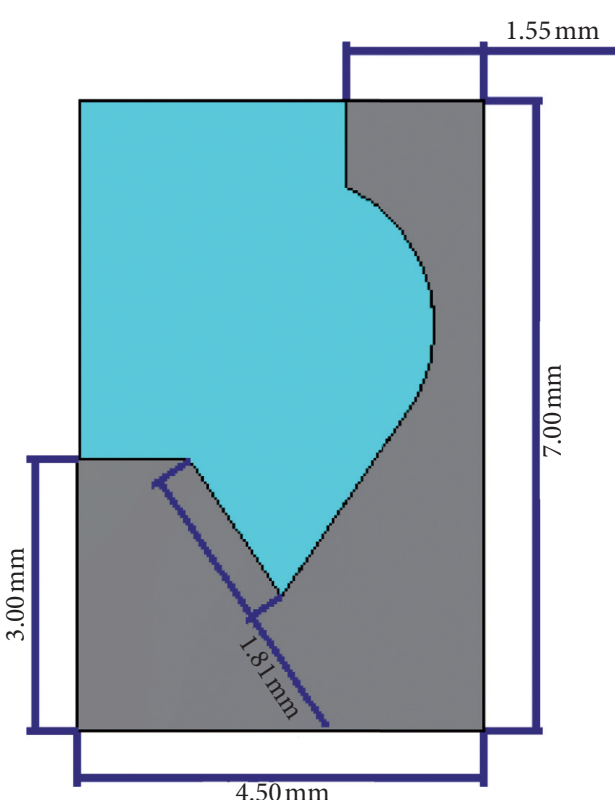

(b)

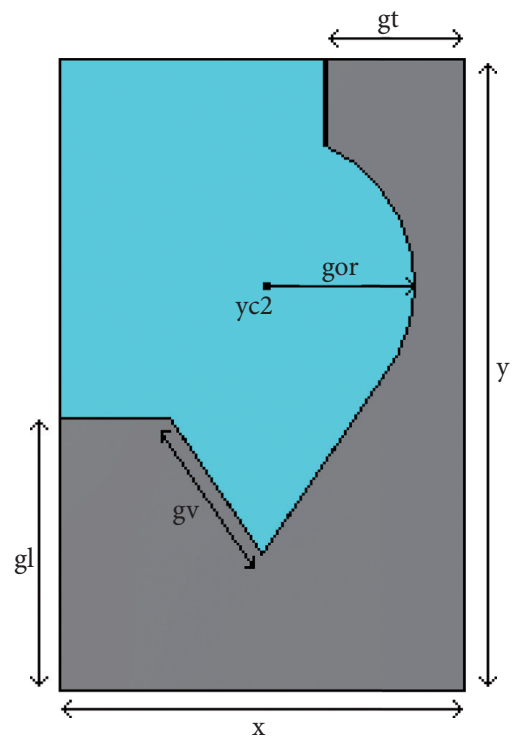

(d)

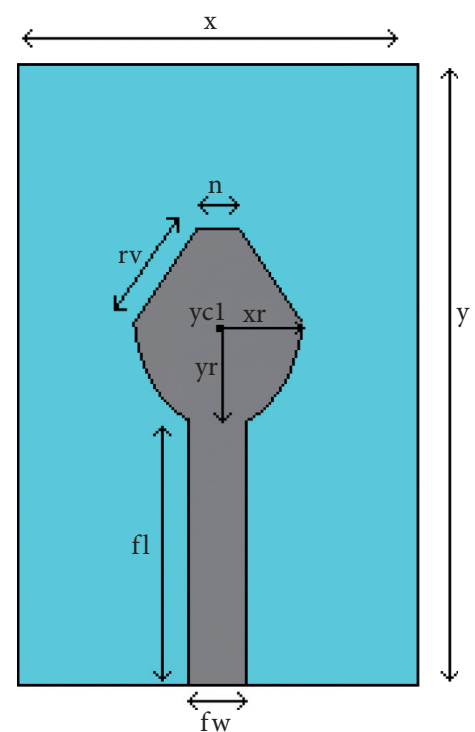

(c)

Figure 2: Dimensions of different parts of the antenna. (a) Front view with dimensions. (b) Back view with dimension. (c) Front view. (d) Back view.

value of 2 over the whole simulated frequency range, and at the resonant frequency, it is less than 1.2 (Figure 3(b)). The antenna's $60 \mathrm{GHz}$ radiation efficiency is around $93 \%$, with a maximum gain of $6.74 \mathrm{dBi}$. The radiation patterns of both planes are shown in Figures 4(a) and 4(b). At this frequency, both E-plane and $\mathrm{H}$-plane radiation patterns show good characteristics with a wide angular width for mmWave antennas. The $\mathrm{H}$-plane has a less noticeable null region compared to the E-plane. Figure 5(a) shows the 3D radiation pattern of the antenna at $60 \mathrm{GHz}$. The $3 \mathrm{D}$ radiation pattern at $60 \mathrm{GHz}$ shows directive radiation toward the $Z$ direction. The associated surface current distribution at $60 \mathrm{GHz}$ is shown in Figure 5(b).
The impedance bandwidth is not affected by the width of the antenna, denoted by " $x$." To demonstrate this behavior, we simulated the antenna by lowering the width of the antenna from $4.5 \mathrm{~mm}$ to 4 and then increasing the width to $5 \mathrm{~mm}$. The return loss magnitudes for these changes are also not affected much. Radiation efficiency and maximum gain increased by a small margin as antenna width increased. The detailed values of these changes are given in Table 3 . Figure 6(a) shows the return loss curves for different widths of the antenna compared to the original design of $4.5 \mathrm{~mm}$. The return loss magnitude at $60 \mathrm{GHz}$ is mainly dependent on the width of the radiating patch "xr." The magnitude increases to $-19.32 \mathrm{~dB}$ for a narrower width of $0.9 \mathrm{~mm}$, while it 
TABLE 1: Antenna dimensions values.

\begin{tabular}{lc}
\hline Parameter & Value (mm) \\
\hline$x$ & 4.5 \\
$y$ & 7 \\
$g l$ & 3 \\
$g v$ & 1.81 \\
$f l$ & 2.98 \\
$f w$ & 0.65 \\
$n$ & 0.47 \\
$r v$ & 1.28 \\
$x r$ & 0.95 \\
$y r$ & 1.35 \\
gor & 1.7 \\
$g t$ & 1.55 \\
\hline
\end{tabular}

TABLE 2: Antenna parts and materials.

\begin{tabular}{lccc}
\hline Antenna part & Thickness $(\mathrm{mm})$ & Material & Relative permittivity \\
\hline Ground & 0.035 & PEC & - \\
Substrate & 1.5 & Cotton & 1.63 \\
Patch radiator & 0.035 & PEC & - \\
\hline
\end{tabular}

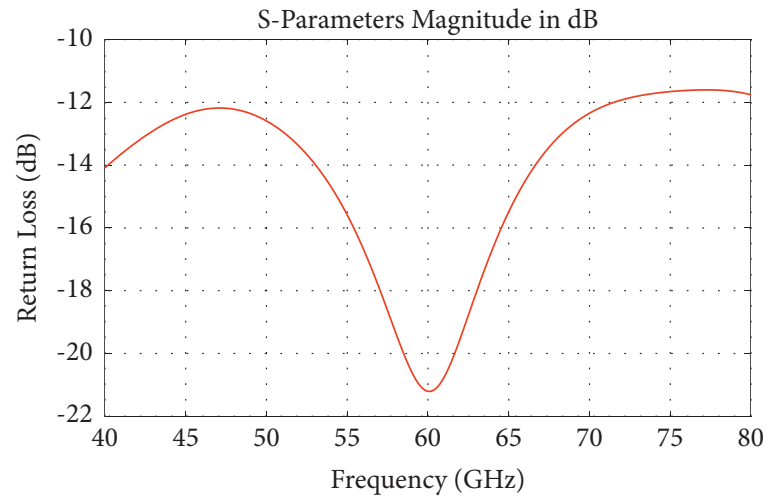

- Free-space

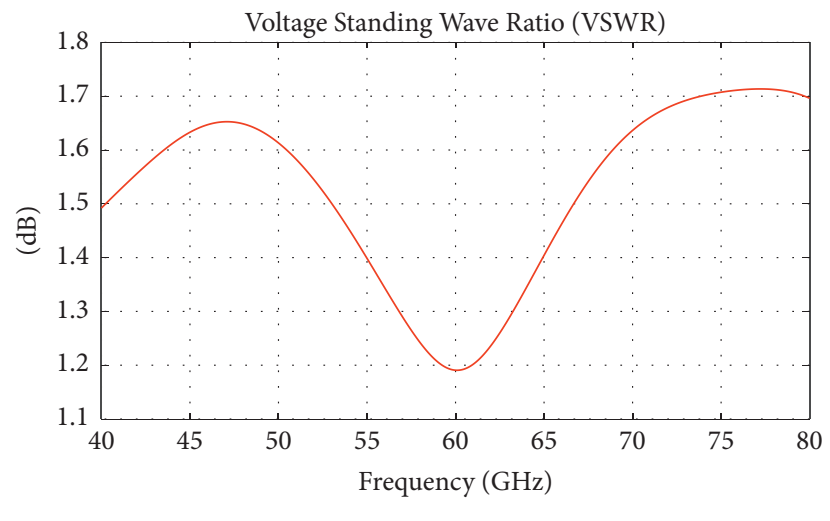

_ Free-space

(a)

(b)

FIgURE 3: (a) Free space return loss and (b) VSWR.

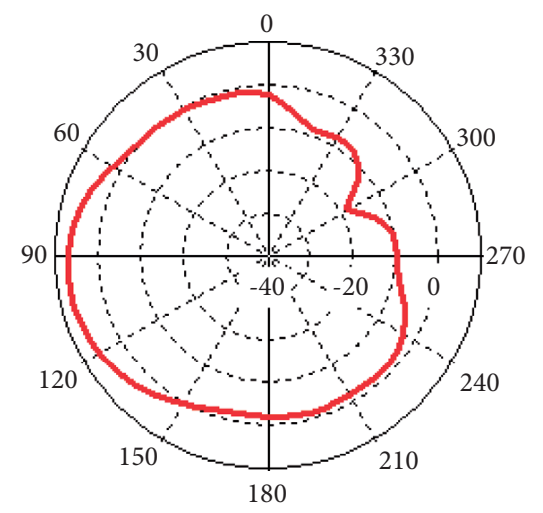

E Plane-Freespace

(a)

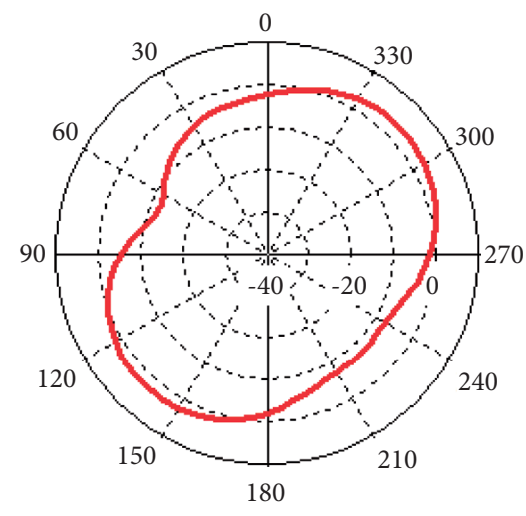

H Plane-Freespace

(b)

Figure 4: $60 \mathrm{GHz}$ radiation pattern. (a) E-plane. (b) H-plane. 


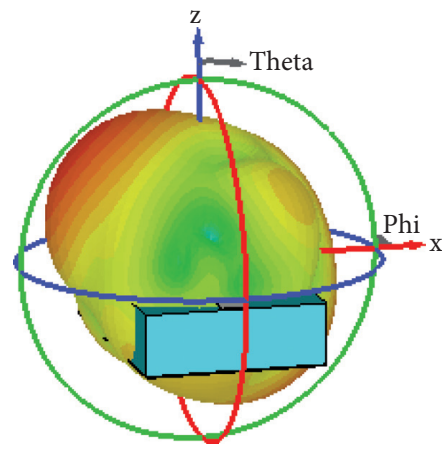

(a)

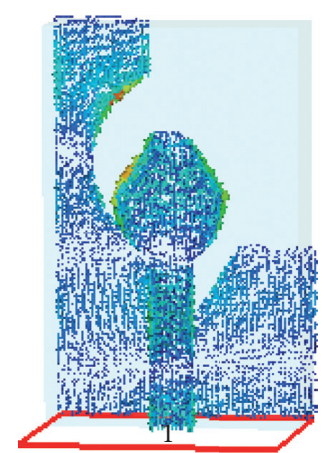

(b)

FIgURE 5: (a) 3D radiation pattern free space at $60 \mathrm{GHz}$ and (b) current distribution at $60 \mathrm{GHz}$.

TABle 3: Antenna width “ $x$ ” changes.

\begin{tabular}{lccc}
\hline Parameters & Free space, $x=4.5 \mathrm{~mm}$ & $x=4 \mathrm{~mm}$ & $x=5 \mathrm{~mm}$ \\
\hline Return loss magnitude at $60 \mathrm{GHz}(\mathrm{dB})$ & -21.20 & -21.39 & -20.97 \\
Bandwidth (GHz) & - & - & - \\
Gain (dBi) & 6.74 & 6.54 & 6.96 \\
Radiation efficiency (\%) & 93.30 & 92.96 & 93.74 \\
\hline
\end{tabular}
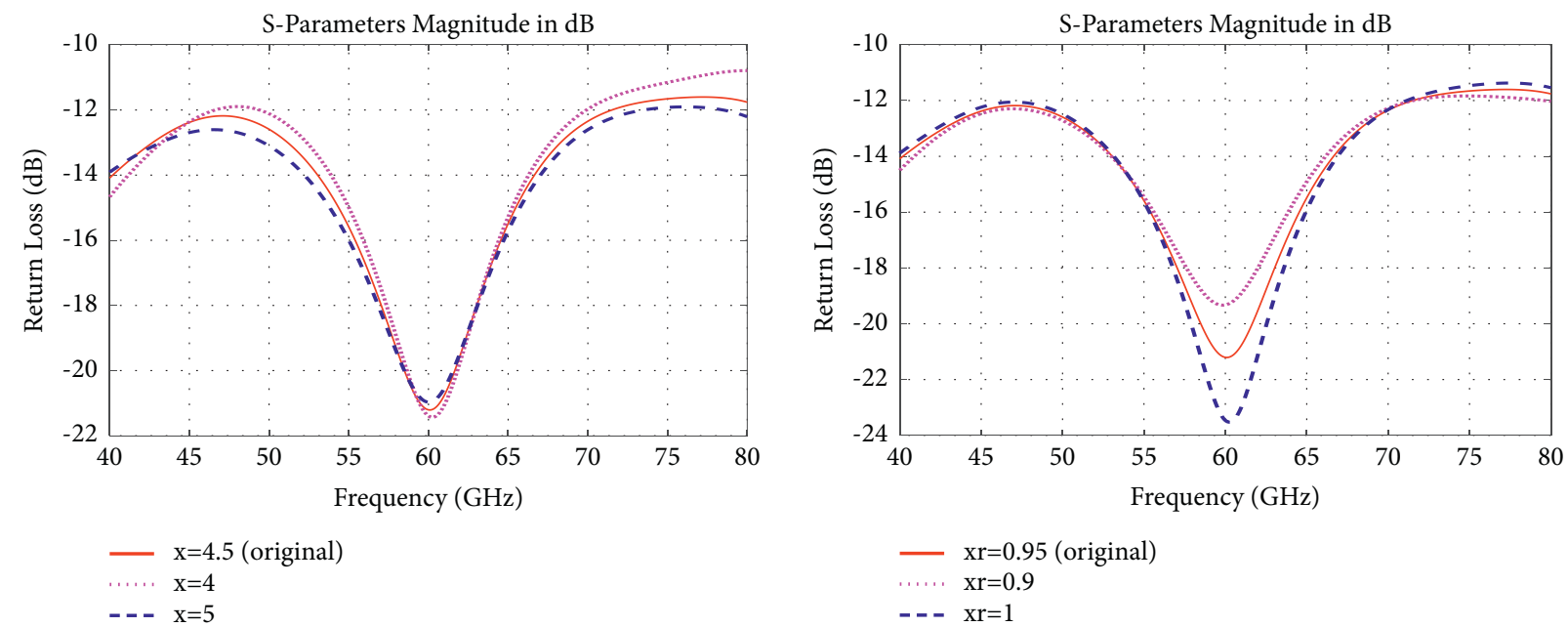

$\begin{array}{ll}\mathrm{xr}=0.95 \text { (original) } \\ \ldots \ldots & \mathrm{xr}=0.9\end{array}$

(a)

(b)

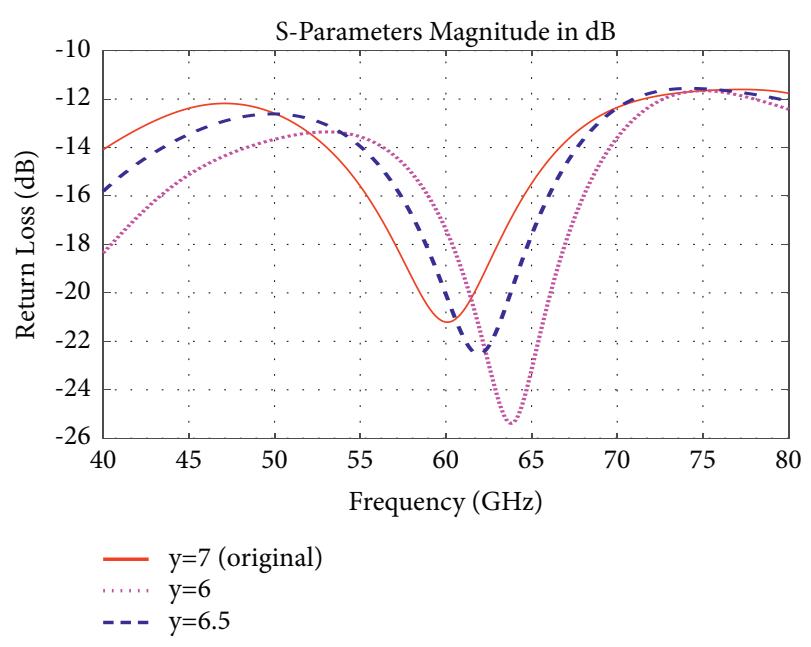

(c)

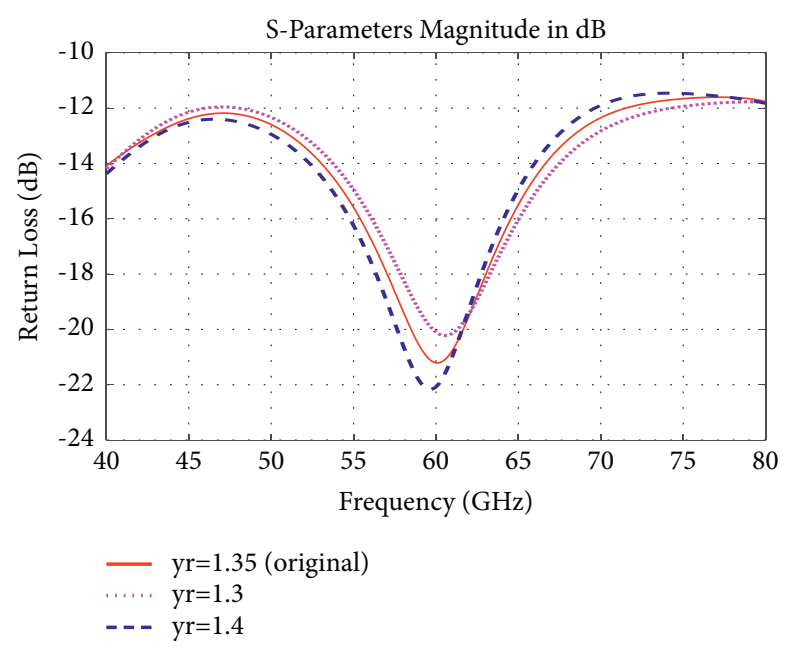

(d)

Figure 6: Return loss comparison for (a) different “ $x$ " values, (b) different “ $x r$ " values, (c) different " $y$ ” values, and (d) different " $y r$ " values. 
TABLE 4: Radiating patch width " $x r$ ” changes.

\begin{tabular}{|c|c|c|c|}
\hline Parameters & Free space, $x r=0.95 \mathrm{~mm}$ & $x r=0.9$ & $x r=1$ \\
\hline Return loss magnitude at $60 \mathrm{GHz}(\mathrm{dB})$ & -21.20 & -19.32 & -23.46 \\
\hline Bandwidth $(\mathrm{GHz})$ & - & - & - \\
\hline Gain $(\mathrm{dBi})$ & 6.74 & 6.79 & 6.70 \\
\hline Radiation efficiency (\%) & 93.30 & 93.26 & 93.30 \\
\hline
\end{tabular}

decreases to $-23.46 \mathrm{~dB}$ for a wider width of $1 \mathrm{~mm}$. The impedance bandwidth, radiation efficiency, and maximum gain remain almost unaffected, suggesting that they are not dependent on this width. Figure 6(b) shows the comparison of return loss curves for different "xr" values, and the details are given in Table 4.

The length of the antenna is denoted by " $y$," and the original design had a length of $7 \mathrm{~mm}$. The resonant frequency of the antenna is dependent on the value of " $y$." The frequency shifts from $60 \mathrm{GHz}$ more toward the right as the " $y$ " value is lowered progressively. The return loss magnitude, maximum gain, and radiation efficiency at $60 \mathrm{GHz}$ also decreased slightly with a lower value of " $y$." The return loss curve comparison is shown in Figure 6(c) and the details are given in Table 5 . The resonant frequency is also dependent on the radiating patch length. The length of the patch can be altered by changing the value of "yr." For smaller lengths, the frequency shifts to the right, and for larger lengths, the frequency shifts more toward the left. The performance parameters are given in Table 6, and the return loss comparison curves for different "yr" values are shown in Figure 6(d).

\section{Body-Centric Simulation Results}

Proper modeling of the human body is vital for the performance evaluation of on-body communications. To minimize the processing time and power consumed by the CST simulation, a human torso phantom was created, measuring $14 \times 9 \mathrm{~mm}^{2}$. The phantom consists of skin, fat, and muscle and has a total thickness of $15 \mathrm{~mm}$ (Figure 7). The detailed physical properties of the phantom at $60 \mathrm{GHz}$ are given in Table 7 [23]. For on-body analysis, the antenna was placed $2 \mathrm{~mm}$ away from the phantom and then was gradually moved away by $2 \mathrm{~mm}$ (Figures $8(\mathrm{a})-8(\mathrm{e})$ ). At the closest distance from the phantom, the resonant frequency shifted toward the left with an increased return loss magnitude. The resonant frequency remained just below $60 \mathrm{GHz}$ for the rest of the distances. The return loss magnitude was close to free space at 6 and $8 \mathrm{~mm}$ from the phantom. The impedance bandwidth remained mostly unchanged for every distance. The return loss curves are compared, as shown in Figure 9. The VSWR at all the distances maintained good, desirable values and is compared, as shown in Figure 10.

The E-plane radiation pattern at $2 \mathrm{~mm}$ shows a few grated lobes being formed compared to free space. Minor lobes are observed away from the phantom (between 0-90 and $0-270^{\circ}$ ), and the back radiation $\left(90-270^{\circ}\right)$ has become distorted with a few null regions. On the other hand, compared to free space, the H-plane was much less distorted in the upper region, with reduced back radiation. As the gap distance between the phantom and the antenna was increased, the radiation pattern was comparable to free space, especially the $\mathrm{H}$-plane pattern at $10 \mathrm{~mm}$. The comparison of the radiation patterns at $2 \mathrm{~mm}$ and the rest of the distances is shown in Figures 11 and 12, respectively. The 3D far-field and the surface current distribution are shown in Figure 13. At $2 \mathrm{~mm}$, the maximum gain dropped by more than $1 \mathrm{~dB}$ and the radiation efficiency dropped by nearly $24 \%$. Due to the lossy human body tissues, the gain and efficiency are reduced when the antenna is placed on the human body model. The maximum gain was highest at $6 \mathrm{~mm}$, and at $10 \mathrm{~mm}$, it was close to the free space result. The gain of this antenna is low at $2 \mathrm{~mm}$ distance from the human body and higher at $10 \mathrm{~mm}$. This is because at a lower gap between the antenna and the body, the antenna has higher effects on the human lossy tissues. The radiation efficiency improved progressively with an increase in the gap distance. The detailed on-body performance values are given in Table 8 . From the results and analysis, it was noted that at $2 \mathrm{~mm}$ and $4 \mathrm{~mm}$ away from the human body model, the antenna provides good performance. Therefore, it is assumed that this antenna can be placed even $2 \mathrm{~mm}$ away from the human body model.

\section{Various Textile Analyses}

Ten different textile substrates were chosen for additional analysis of the antenna design by varying the relative permittivity and thickness. The list of these substrates along with their free space simulation results is given in Table 9. Figure 14 shows the return loss comparison between these textiles. Tween and panama achieved a resonant frequency very close to the cotton substrate. The resonance frequency shifted to the right for silk, jeans, moleskin, and felt. The radiation efficiencies increased while the maximum gain saw reduced values. The $60 \mathrm{GHz}$ return loss magnitude was reduced for Quartzel, Cordura/Lycra, 100\% polyester, and denim, while the resonant frequency shifted to the left. Denim, $100 \%$ polyester, and Quartzel's maximum gain were similar to cotton. All ten textile substrates maintained radiation efficiency above $92 \%$. The radiation patterns showed no significant changes when compared to cotton. In both E-plane and H-plane, Cordura/Lycra showed a better omnidirectional radiation pattern than the rest of the substrates (Figure 15).

On-body simulation results are given in Table 10. The return loss curves are compared, as shown in Figure 16. The return loss magnitude at $60 \mathrm{GHz}$ was affected by the phantom, while the resonant frequency also experienced shifts. The maximum gain increased significantly for jeans, 
TABle 5: Antenna length " $y$ ” changes.

\begin{tabular}{lccc}
\hline Parameters & Free space, $y=7 \mathrm{~mm}$ & $y=6 \mathrm{~mm}$ & \multicolumn{1}{c}{$y=6.5 \mathrm{~mm}$} \\
\hline Return loss magnitude at $60 \mathrm{GHz}(\mathrm{dB})$ & -21.20 & -17.39 & - \\
Bandwidth (GHz) & - & 6.40 & -20.06 \\
Gain (dBi) & 6.74 & 90.61 & 6.58 \\
Radiation efficiency (\%) & 93.30 & 91.91 \\
\hline
\end{tabular}

TABLE 6: Radiating patch length "yr" changes.

\begin{tabular}{lccc}
\hline Parameters & Free space, $y r=1.35 \mathrm{~mm}$ & $y r=1.3 \mathrm{~mm}$ & \\
\hline Return loss magnitude at $60 \mathrm{GHz}(\mathrm{dB})$ & -21.20 & -20.09 & $-2.4 \mathrm{~mm}$ \\
Bandwidth (GHz) & - & - & - \\
Gain (dBi) & 6.74 & 6.77 & 6.70 \\
Radiation efficiency (\%) & 93.30 & 93.02 & 93.56 \\
\hline
\end{tabular}

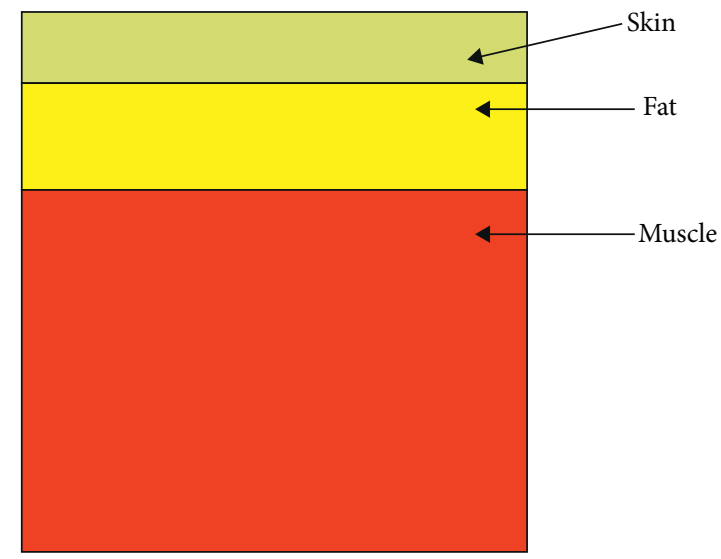

FIgURE 7: A three-layer human torso phantom.

TABle 7: Torso phantom dimensions values.

\begin{tabular}{lccccc}
\hline Parameter & Length $(\mathrm{mm})$ & Width $(\mathrm{mm})$ & Thickness $(\mathrm{mm})$ & Relative permittivity & Conductivity $(\mathrm{S} / \mathrm{m})$ \\
\hline Skin & 14 & 9 & 2 & 7.98 & 36.40 \\
Fat & 14 & 9 & 3 & 3.13 & 2.82 \\
Muscle & 14 & 9 & 10 & 12.86 & 52.83 \\
\hline
\end{tabular}

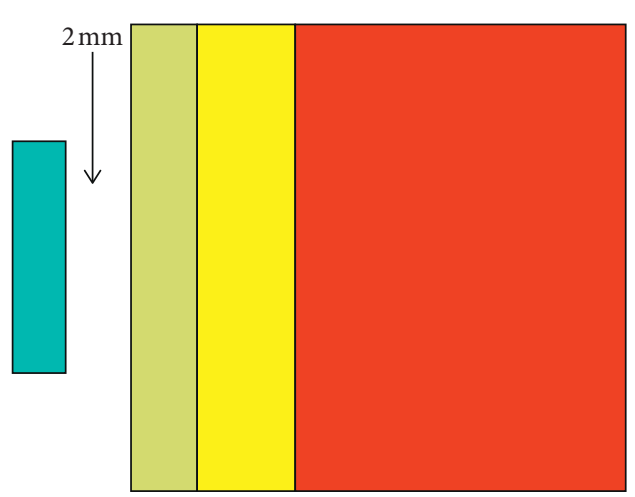

(a)

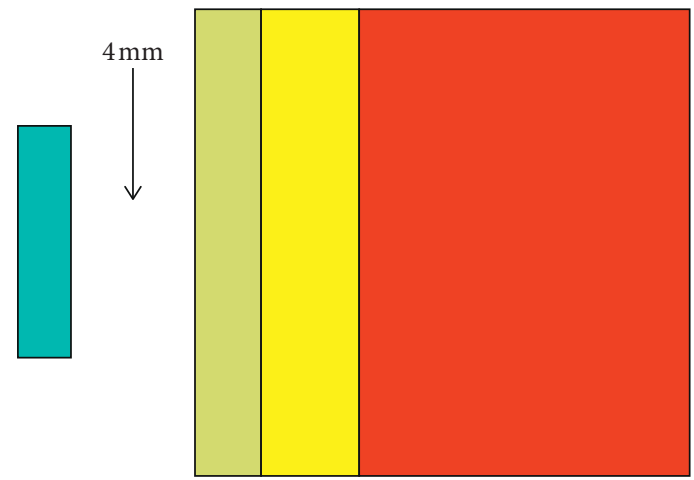

(b)

Figure 8: Continued. 


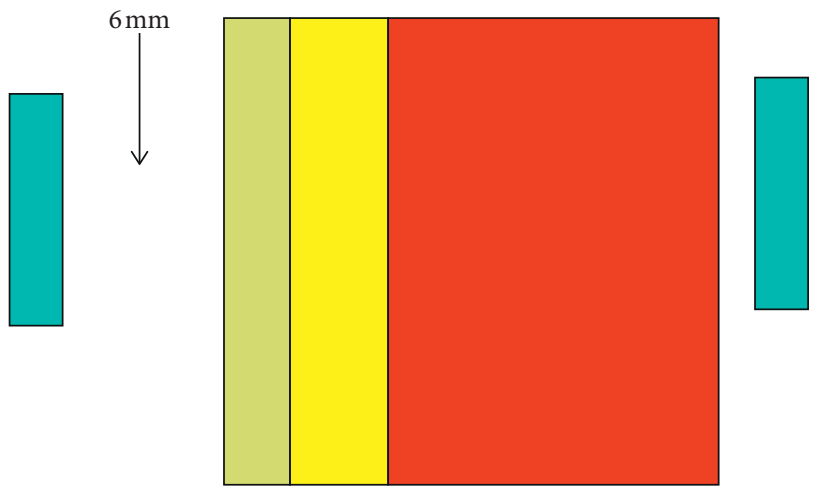

(c)

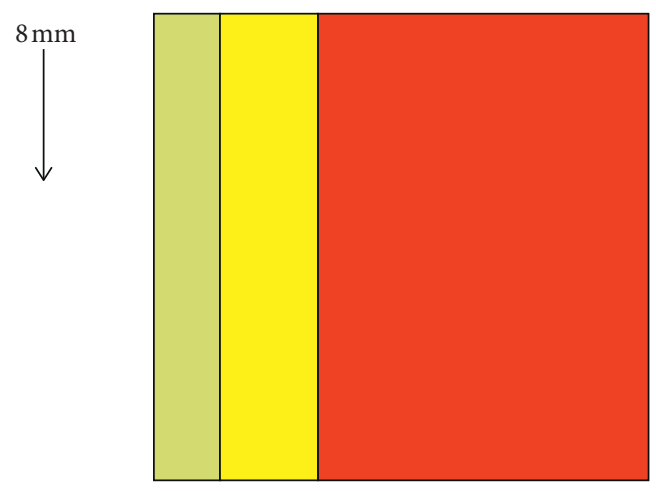

(d)
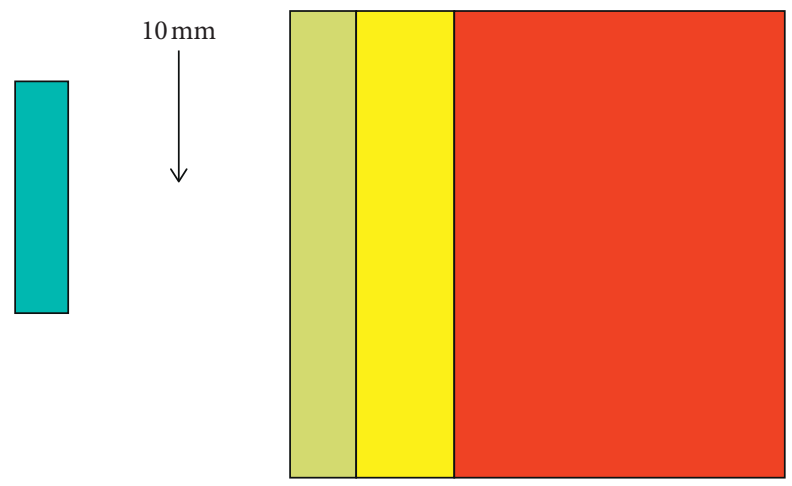

(e)

Figure 8: On-body antenna distances from the phantom.

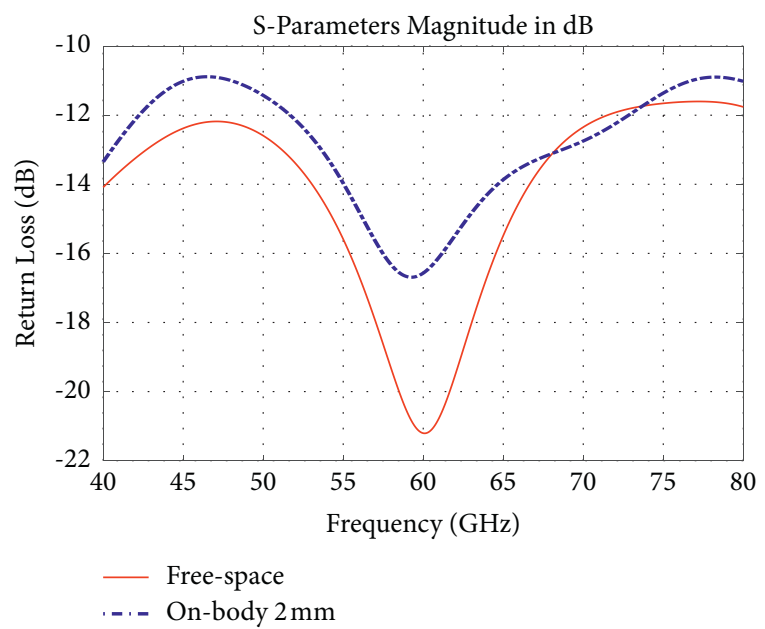

(a)

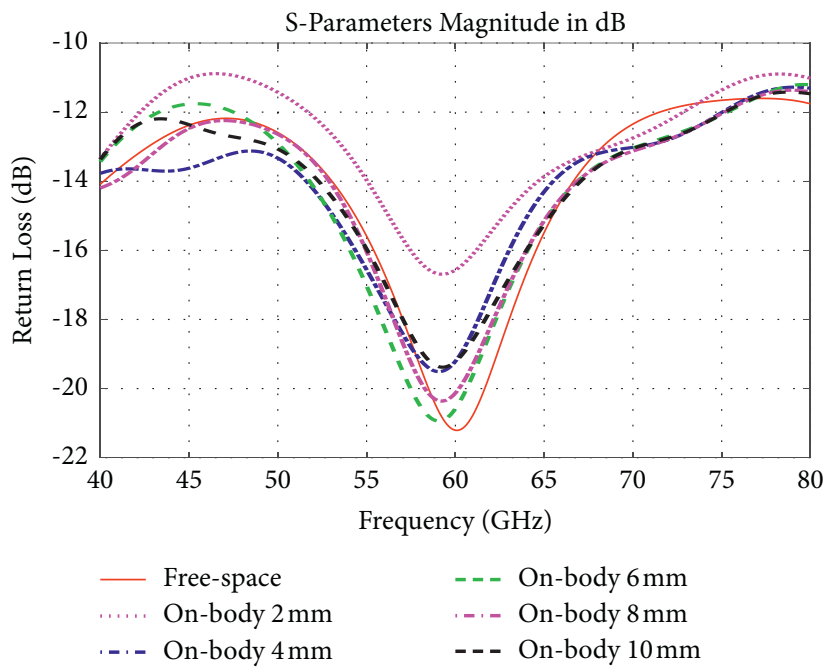

(b)

FiguRE 9: On-body return loss comparison with free space. (a) $2 \mathrm{~mm}$ away from the phantom. (b) Five different distances away from the phantom.

silk, moleskin, and Cordura/Lycra. The E-plane and H-plane radiation patterns are comparable to free space. Eventhough a few grated lobes are formed, the back radiation toward the phantom is reduced (Figure 17). Radiation efficiency is significantly affected by the presence of the phantom.

\section{Comparison with Previous Works}

The proposed design is compared with the work presented in $[9,10,21] .60 \mathrm{GHz}$ textile antennas based on cotton are very rare. The 4-element patch array presented in [9] is built on a 


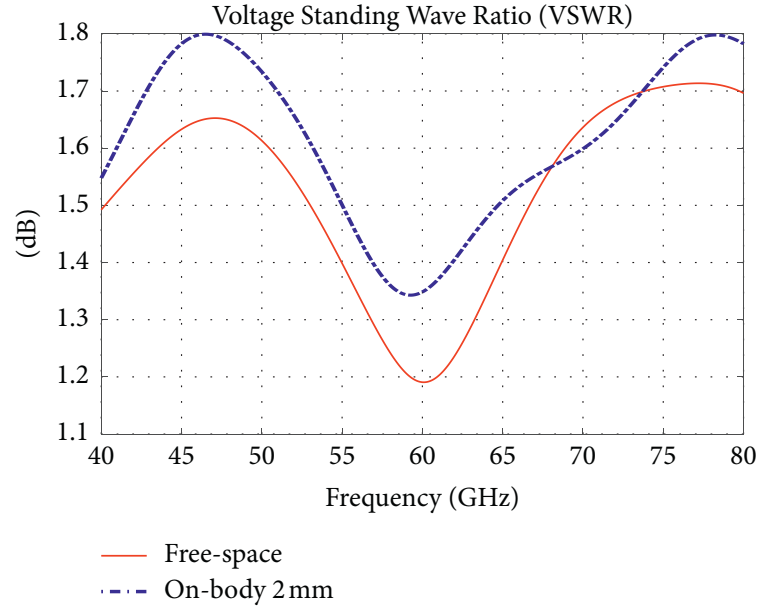

(a)

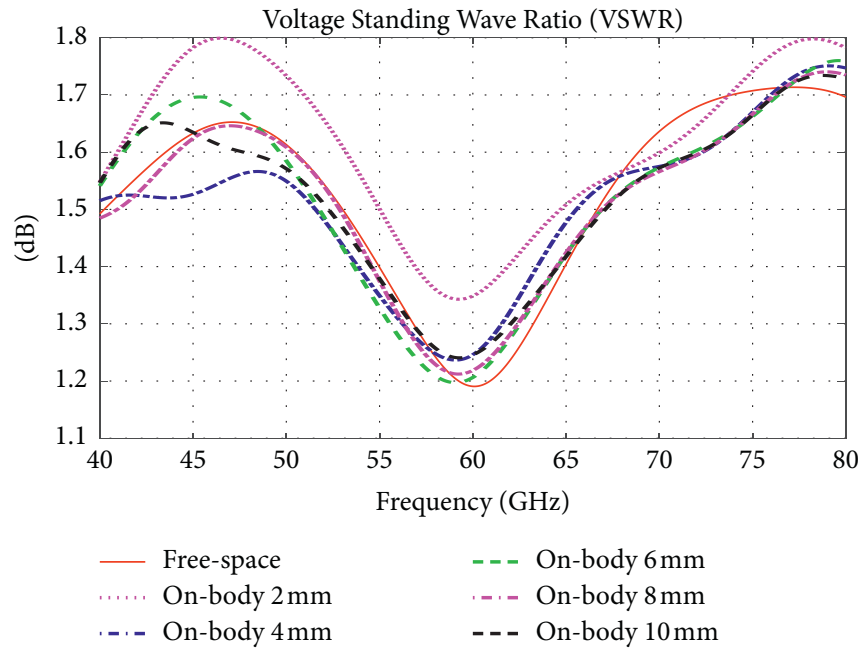

(b)

Figure 10: On-body VSWR comparison with free space. (a) $2 \mathrm{~mm}$ away from the phantom. (b) Five different distances away from the phantom.

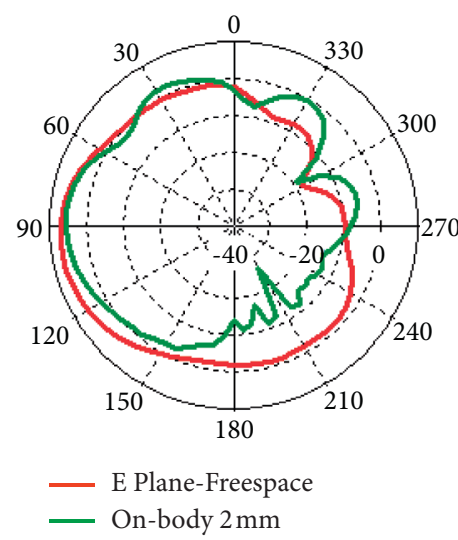

(a)

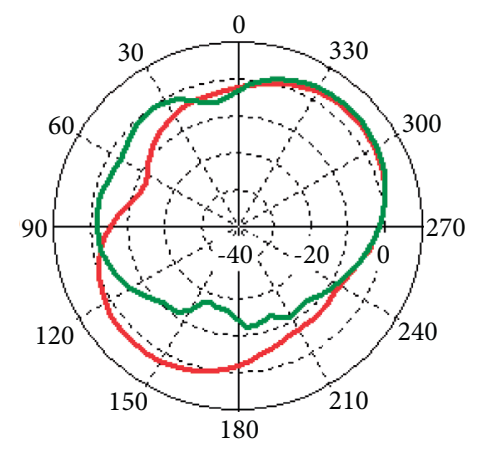

H Plane-Freespace

- On-body $2 \mathrm{~mm}$

(b)

FIGURE 11: $60 \mathrm{GHz}$ radiation pattern comparison at $2 \mathrm{~mm}$ away from the phantom. (a) E-plane. (b) H-plane.

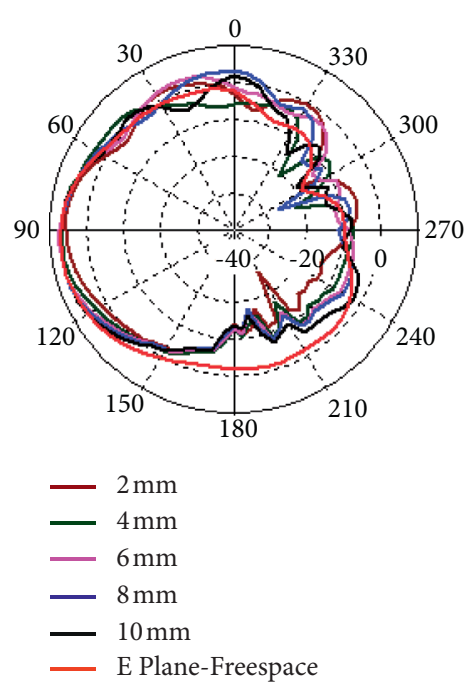

(a)
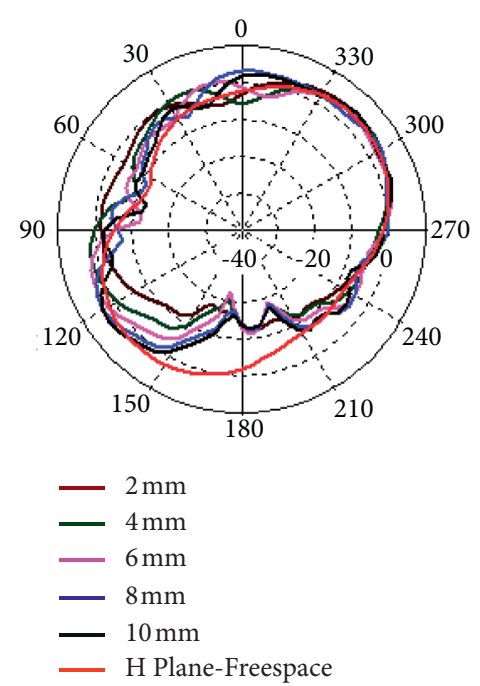

(b)

FIGURE 12: $60 \mathrm{GHz}$ radiation pattern comparison at five different distances away from the phantom. (a) E-plane. (b) H-plane. 


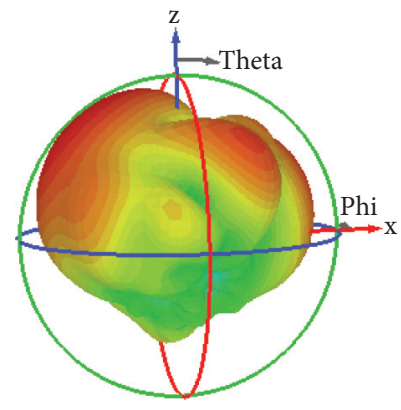

(a)

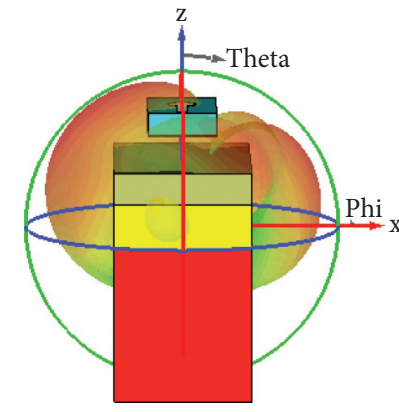

(b)

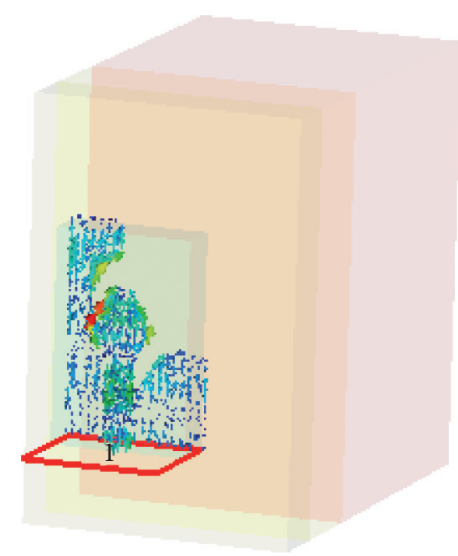

(c)

Figure 13: (a) Far-field 3D view on-body $4 \mathrm{~mm}$ far without, (b) with structure, and (c) surface current for $60 \mathrm{GHz}$.

TABLE 8: On-body antenna performance.

\begin{tabular}{|c|c|c|c|c|c|c|}
\hline Parameters & Free space & On-body $2 \mathrm{~mm}$ & On-body $4 \mathrm{~mm}$ & On-body $6 \mathrm{~mm}$ & On-body $8 \mathrm{~mm}$ & On-body $10 \mathrm{~m}$ \\
\hline Return loss magnitude at $60 \mathrm{GHz}(\mathrm{dB})$ & -21.20 & -16.57 & -19.21 & -20.58 & -20.13 & -19.22 \\
\hline Bandwidth $(\mathrm{GHz})$ & - & - & - & - & - & - \\
\hline Gain $(\mathrm{dBi})$ & 6.74 & 5.23 & 6.56 & 7.04 & 6.88 & 6.69 \\
\hline Radiation efficiency (\%) & 93.30 & 69.20 & 81.28 & 86.23 & 88.83 & 90.28 \\
\hline
\end{tabular}

TABLE 9: Free space performance comparison among different textile substrates.

\begin{tabular}{|c|c|c|c|c|c|c|}
\hline Substrate & $\begin{array}{c}\text { Relative } \\
\text { permittivity }\end{array}$ & $\begin{array}{l}\text { Thickness } \\
(\mathrm{mm})\end{array}$ & $\begin{array}{l}\text { Return loss magnitude at } \\
60 \mathrm{GHz}(\mathrm{dB})\end{array}$ & $\begin{array}{l}\text { Bandwidth } \\
(\mathrm{GHz})\end{array}$ & $\begin{array}{l}\text { Gain } \\
(\mathrm{dBi})\end{array}$ & $\begin{array}{c}\text { Radiation efficiency } \\
(\%)\end{array}$ \\
\hline Cotton & 1.63 & 1.5 & -21.20 & - & 6.74 & 93.30 \\
\hline Jeans & 1.7 & 1 & -20.46 & - & 5.96 & 94.78 \\
\hline Denim & 1.87813 & 1.5 & -15.35 & - & 6.65 & 92.67 \\
\hline Silk & 1.75 & 1.16 & -27.52 & - & 5.50 & 94.01 \\
\hline Tween & 1.69 & 1.37 & -25.10 & - & 6.20 & 93.56 \\
\hline Panama & 2.12 & 1.04 & -31.62 & - & 5.58 & 93.81 \\
\hline Felt & 1.38 & 1.38 & -19.80 & - & 5.77 & 94.47 \\
\hline Moleskin & 1.45 & 1.17 & -20.81 & - & 5.70 & 94.96 \\
\hline $\begin{array}{l}100 \% \\
\text { polyester }\end{array}$ & 1.9 & 1.5 & -14.92 & - & 6.62 & 92.59 \\
\hline $\begin{array}{l}\text { Quartzel } \\
\text { fabric }\end{array}$ & 1.95 & 1.5 & -13.80 & - & 6.55 & 93.12 \\
\hline $\begin{array}{l}\text { Cordura/ } \\
\text { Lycra }\end{array}$ & 1.5 & 0.5 & -15.05 & - & 6.33 & 96.61 \\
\hline
\end{tabular}

$0.2 \mathrm{~mm}$ thick cotton fabric extracted from a shirt. The measured relative permittivity showed that the cotton fabric has a value of 2 . The radiating elements and the ground plane are made from $0.07 \mathrm{~mm}$ thin copper foil. In [10], a Yagi-Uda antenna based on $0.2 \mathrm{~mm}$ thick cotton fabric achieved an end-fire radiation pattern suitable for WBAN applications. The overall dimension of the antenna is $26 \times 8 \times 0.2 \mathrm{~mm}^{3}$. The antenna achieved a simulated gain of $9 \mathrm{dBi}$ and an efficiency of $74 \%$. The slotted patch antenna presented in [21] was also simulated using a $1.5 \mathrm{~mm}$ thick cotton substrate. The dimension of the antenna is $12.2 \times 12 \times 1.57 \mathrm{~mm}^{3}$. On a three-layer torso-equivalent phantom, the antenna's gain and efficiency were $5.96 \mathrm{dBi}$ and $58.03 \%$, respectively. The antenna presented in [22] is printed on an FR-4 substrate, and it is bigger in size than the proposed antenna in this study.

In comparison, the design presented in this study has a wider bandwidth. Eventhough the maximum gain was lower, the antenna was much more efficient. The major advantage of this design is its planar size. Compared to the reported work, this antenna is significantly smaller in terms of length and width. The thickness and relative permittivity of the cotton substrate will vary depending on the source and manufacturing techniques used. Table 11 provides the comparison of this work with other articles.

The main limitation was the measurement, which was outside the scope of the authors. The measurement facility 

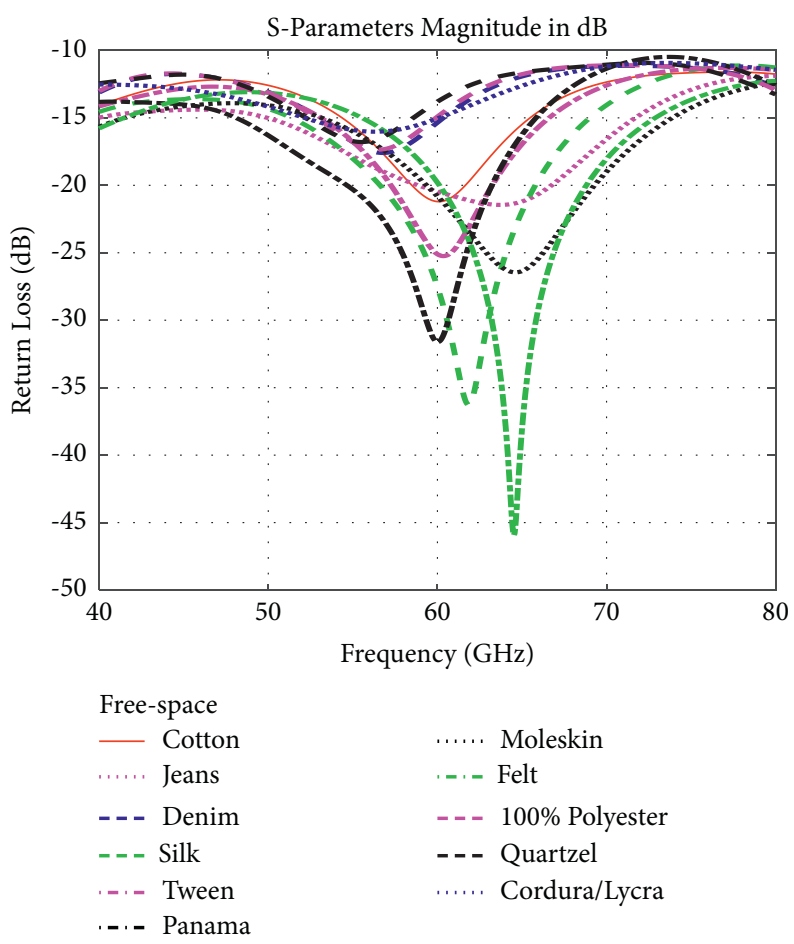

FIGURE 14: Free space return loss comparison between different textile substrates.
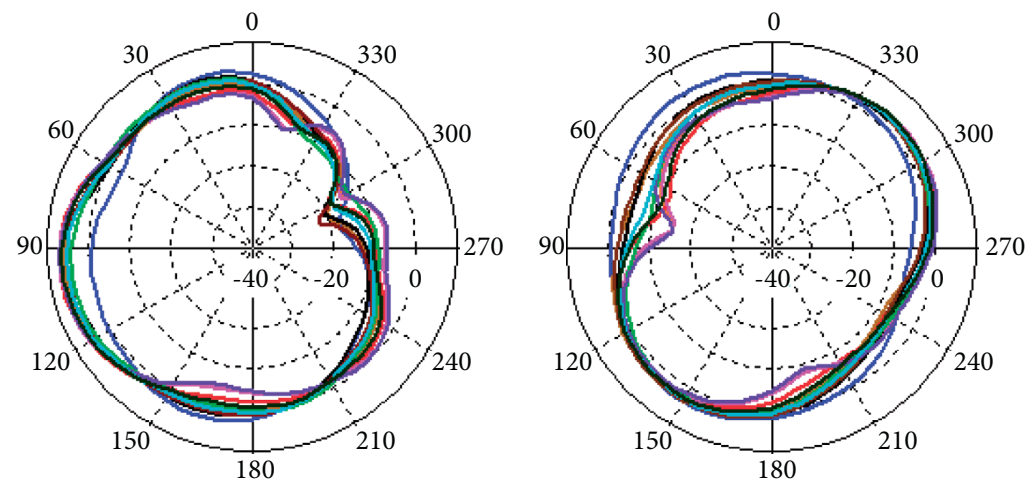

E-Plane

H-Plane
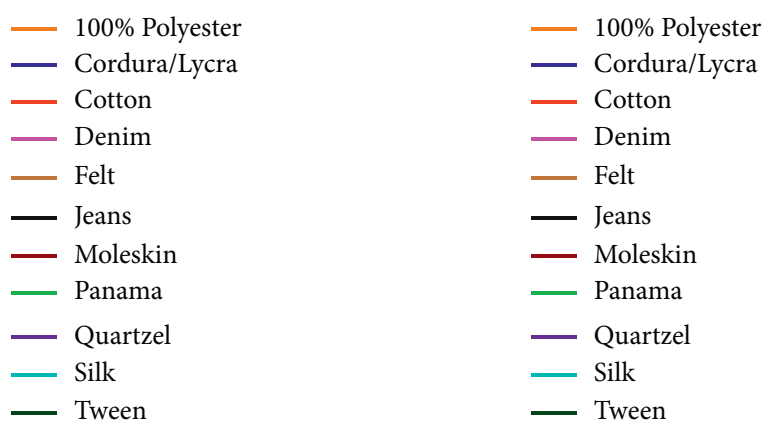

(a)

(b)

FIGURE 15: Free space $60 \mathrm{GHz}$ radiation pattern of different textile substrates. (a) E-plane. (b) H-plane.

for a very high frequency range is not available here in Bangladesh. The CST software is very user-friendly, and the results obtained using this software are reliable. From the previous studies, it is noted that the simulation results for antennas obtained using CST are comparable to measurements [23-27]. 
TABLE 10: On-body performance comparison between different textile substrates.

\begin{tabular}{|c|c|c|c|c|c|c|}
\hline Substrate & $\begin{array}{c}\text { Relative } \\
\text { permittivity }\end{array}$ & $\begin{array}{l}\text { Thickness } \\
(\mathrm{mm})\end{array}$ & $\begin{array}{l}\text { Return loss magnitude at } \\
60 \mathrm{GHz}(\mathrm{dB})\end{array}$ & $\begin{array}{l}\text { Bandwidth } \\
\text { (GHz) }\end{array}$ & $\begin{array}{l}\text { Gain } \\
(\mathrm{dBi})\end{array}$ & $\begin{array}{c}\text { Radiation efficiency } \\
(\%)\end{array}$ \\
\hline Cotton & 1.63 & 1.5 & -16.57 & - & 5.28 & 69.20 \\
\hline Jeans & 1.7 & 1 & -18.55 & - & 8.29 & 67.29 \\
\hline Denim & 1.87813 & 1.5 & -12.92 & - & 5.04 & 71.94 \\
\hline Silk & 1.75 & 1.16 & -21.50 & - & 7.09 & 66.17 \\
\hline Tween & 1.69 & 1.37 & -17.85 & - & 5.62 & 67.65 \\
\hline Panama & 2.12 & 1.04 & -24.75 & - & 6.66 & 67.15 \\
\hline Felt & 1.38 & 1.38 & -17.20 & - & 6.97 & 66.61 \\
\hline Moleskin & 1.45 & 1.17 & -17.64 & - & 7.89 & 66.29 \\
\hline $\begin{array}{l}100 \% \\
\text { polyester }\end{array}$ & 1.9 & 1.5 & -12.68 & - & 5.00 & 71.19 \\
\hline $\begin{array}{l}\text { Quartzel } \\
\text { fabric }\end{array}$ & 1.95 & 1.5 & -12.22 & - & 4.89 & 72.65 \\
\hline $\begin{array}{l}\text { Cordura/ } \\
\text { Lycra }\end{array}$ & 1.5 & 0.5 & -12.46 & - & 9.65 & 74.11 \\
\hline
\end{tabular}

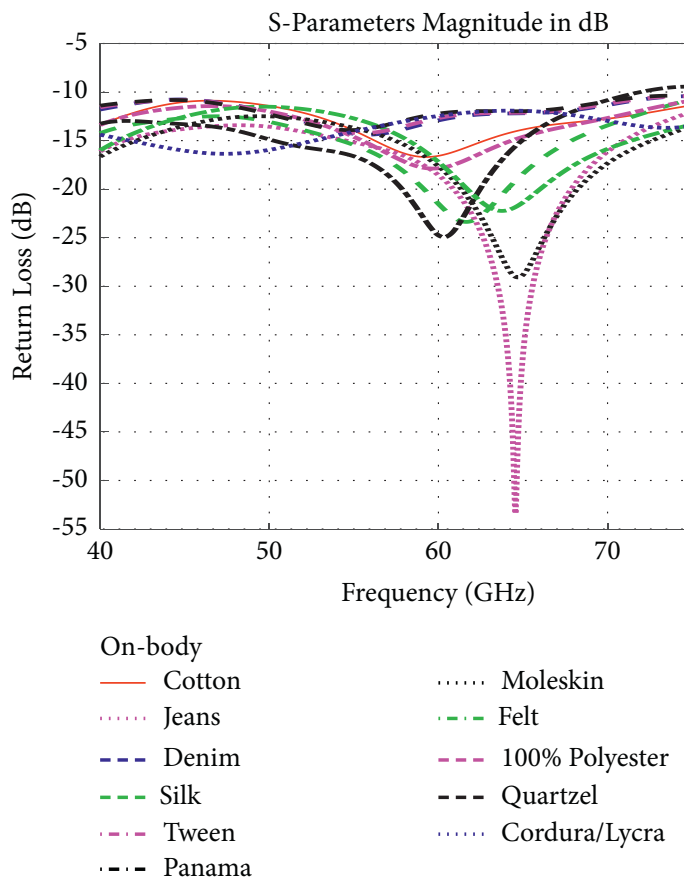

Figure 16: On-body return loss comparison between different textile substrates. 

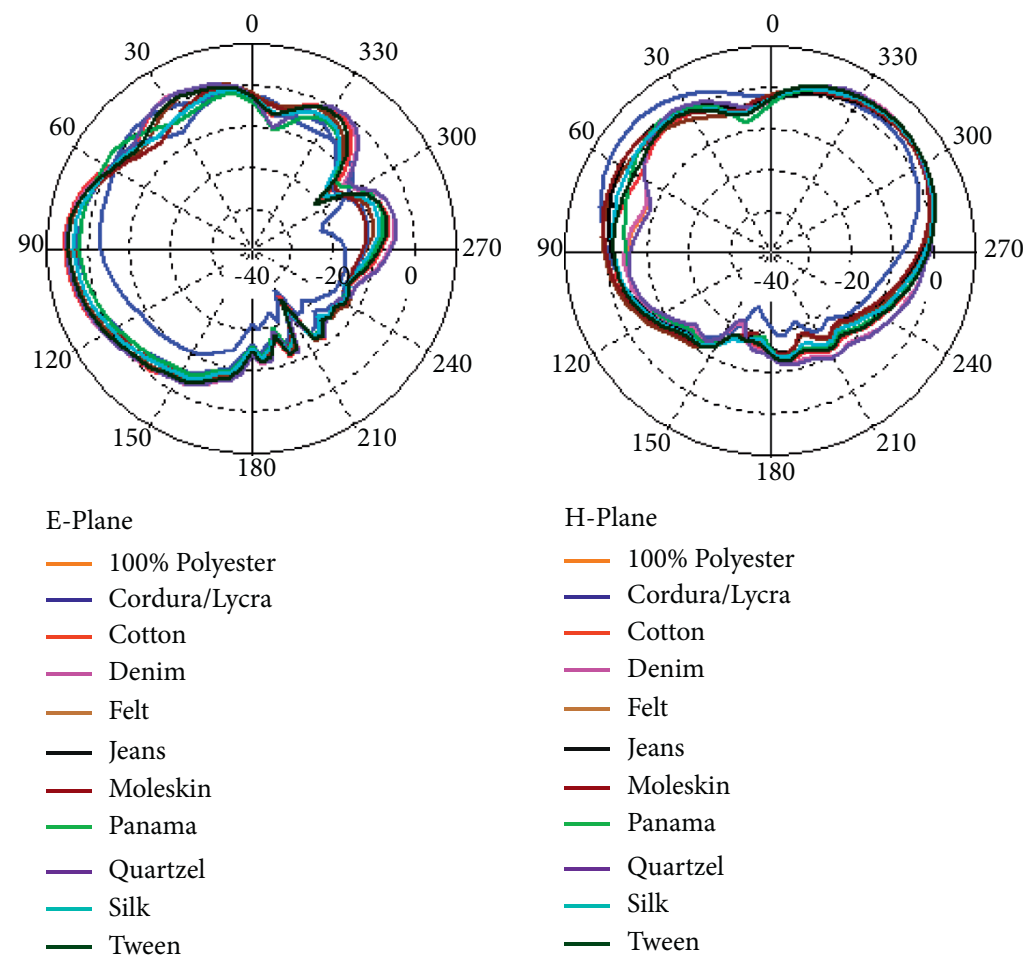

H-Plane

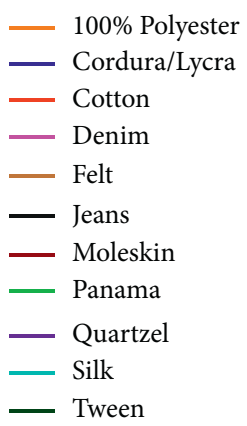

(a)

(b)

Figure 17: On-body $60 \mathrm{GHz}$ radiation pattern of different textile substrates. (a) E-plane. (b) H-plane.

TABLE 11: Comparison with other articles.

\begin{tabular}{|c|c|c|c|c|c|c|c|}
\hline Antenna & $\begin{array}{l}\text { Size length (L) and width } \\
(\mathrm{W}), \mathrm{mm}\end{array}$ & $\begin{array}{c}\text { Relative } \\
\text { permittivity }\end{array}$ & $\begin{array}{c}\text { Substrate } \\
\text { material }\end{array}$ & $\begin{array}{l}\text { Bandwidth }(\mathrm{GHz}) \text { at } \\
-10 \mathrm{~dB}\end{array}$ & $\begin{array}{l}\text { Gain } \\
(\mathrm{dBi}) \\
\end{array}$ & $\begin{array}{c}\text { Efficiency } \\
(\%)\end{array}$ & $\begin{array}{c}\text { Antenna } \\
\text { type }\end{array}$ \\
\hline $\begin{array}{l}\text { Reference } \\
{[9]}\end{array}$ & $50 x^{*}$ & 2 & Cotton & $55-65$ & 8.6 & 41 & Array \\
\hline $\begin{array}{l}\text { Reference } \\
{[10]}\end{array}$ & $26 \times 8$ & 1.5 & Cotton & $57-64$ & 9 & 74 & Yagi-Uda \\
\hline $\begin{array}{l}\text { Reference } \\
{[21]}\end{array}$ & $12.2 \times 12$ & 1.9 & $100 \%$ polyester & 11.632 & 5.96 & 58.03 & $\begin{array}{l}\text { Slotted } \\
\text { patch }\end{array}$ \\
\hline $\begin{array}{l}\text { Reference } \\
{[22]}\end{array}$ & $12.9 \times 14$ & 4.3 & FR-4 & 12.11 & 8.62 & 82.15 & Q-slot \\
\hline This study & $7 \times 4.5$ & 1.63 & Cotton & $40-80$ & 6.74 & 93.3 & $\begin{array}{c}\text { Single } \\
\text { antenna }\end{array}$ \\
\hline
\end{tabular}

${ }^{*}$ Exact value not provided.

\section{Conclusion}

The goal of this study was to design and analyze a tiny and novel $60 \mathrm{GHz}$ textile antenna based on a cotton substrate. This study shows the comprehensive results and analysis of this antenna. Compared to a previous work, the proposed antenna design is very compact and achieves a very wide impedance bandwidth. The resonant frequency is dependent on the length of the antenna and the radiating patch. The maximum gain value achieved by the antenna suggests that the data transmission over a longer distance will be affected. The antenna's radiation efficiency was heavily affected by the influence of a human torso phantom. The cotton substrate was replaced by different textile substrates, among which tween and panama achieved very similar results to cotton. On the human body, this compact and novel-shaped antenna shows very good performance. For body-centric wireless communications in e-health applications, the antenna needs to be very compact in size, less sensitive, and efficient. The textile antenna is a very good choice for bodycentric communications in e-health applications. To the knowledge of the authors of this study, this proposed antenna is the smallest mmWave textile antenna with good performance so far. This tiny cotton-based textile antenna will be a very good choice for body-centric communications in healthcare applications. In the future, the bending characteristics of the antenna can be investigated. In addition, the antenna design can be optimized to work in other 
frequency bands. The antenna can also be designed as an array for e-health applications.

\section{Data Availability}

The data used to support the findings of this study are freely available at http://niremf.ifac.cnr.it/tissprop/.

\section{Conflicts of Interest}

The authors declare that they have no conflicts of interest.

\section{Acknowledgments}

The authors are thankful for the support from Taif University Researchers Supporting Project (TURSP-2020/26), Taif University, Taif, Saudi Arabia.

\section{References}

[1] N. Chahat, M. Zhadobov, and R. Sauleau, "Broadband tissueequivalent phantom for BAN applications at millimeter waves," IEEE Transactions on Microwave Theory and Techniques, vol. 60, no. 7, pp. 2259-2266, 2012.

[2] C. Leduc and M. Zhadobov, "Impact of antenna topology and feeding technique on coupling with human body: application to $60-\mathrm{GHz}$ antenna arrays," IEEE Transactions on Antennas and Propagation, vol. 65, no. 12, pp. 6779-6787, 2017.

[3] J. Puskely, M. Pokorny, J. Lacik, and Z. Raida, "Wearable disclike antenna for body-centric communications at $61 \mathrm{GHz}$," IEEE Antennas and Wireless Propagation Letters, vol. 14, pp. 1490-1493, 2015.

[4] X. Y. Wu, L. Akhoondzadeh-Asl, Z. P. Wang, and P. S. Hall, "Novel Yagi-Uda antennas for on-body communication at $60 \mathrm{GHz}$," in Proceedings of the Loughborough Antennas \& Propagation Conference, pp. 153-156, Loughborough, UK, 2010.

[5] B. Almohammed, A. Ismail, and A. Sali, "Electro-textile wearable antennas in wireless body area networks: materials, antenna design, manufacturing techniques, and human body consideration-a review," Textile Research Journal, vol. 91, no. 5-6, pp. 646-663, 2021.

[6] S. Li and J. Li, "Smart patch wearable antenna on Jeans textile for body wireless communication," in Proceedings of the 12th International Symposium on Antennas, Propagation and EM Theory (ISAPE), pp. 1-4, Hangzhou, China, 2018.

[7] C. K. Nanda, S. Ballav, A. Chatterjee, and S. K. Parui, "A body wearable antenna based on jeans substrate with wide-band response," in Proceedings of the 5th International Conference on Signal Processing and Integrated Networks (SPIN), pp. 474-477, Noida, India, 2018.

[8] M. A. R. Osman, M. K. A. Rahim, N. A. Samsuri, M. K. Elbasheer, and M. E. Ali, "Textile UWB antenna bending and wet performances," International Journal of Antennas and Propagation, vol. 2012, Article ID 251682, 12 pages, 2012.

[9] N. Chahat, M. Zhadobov, S. A. Muhammad, L. Le Coq, and R. Sauleau, "60-GHz textile antenna array for body-centric communications," IEEE Transactions on Antennas and Propagation, vol. 61, no. 4, pp. 1816-1824, 2013.

[10] N. Chahat, M. Zhadobov, L. Le Coq, and R. Sauleau, "Wearable endfire textile antenna for on-body communications at $60 \mathrm{GHz}$," IEEE Antennas and Wireless Propagation Letters, vol. 11, pp. 799-802, 2012.

[11] M. Klemm and G. Troester, "Textile UWB antennas for wireless body area networks," IEEE Transactions on Antennas and Propagation, vol. 54, no. 11, pp. 3192-3197, 2006.

[12] N. Chahat, M. Zhadobov, L. Le Coq, S. I. Alekseev, and R. Sauleau, "Characterization of the interactions between a $60-\mathrm{GHz}$ antenna and the human body in an off-body scenario," IEEE Transactions on Antennas and Propagation, vol. 60, no. 12, pp. 5958-5965, 2012.

[13] N. Chahat, G. Valerio, M. Zhadobov, and R. Sauleau, "Onbody propagation at $60 \mathrm{GHz}$," IEEE Transactions on Antennas and Propagation, vol. 61, no. 4, pp. 1876-1888, 2013.

[14] X. Lin, Y. Chen, Z. Gong, B.-C. Seet, L. Huang, and Y. Lu, "Ultrawideband textile antenna for wearable microwave medical imaging applications," IEEE Transactions on Antennas and Propagation, vol. 68, no. 6, pp. 4238-4249, 2020.

[15] K. Wang and J. Li, "Jeans textile antenna for smart wearable antenna," in Proceedings of the 12th International Symposium on Antennas, Propagation and EM Theory (ISAPE), pp. 1-3, Hangzhou, China, December 2018.

[16] R. Wu, H. Tang, K. Wang, C. Yu, J. Zhang, and X. Wang, "Eshaped array antenna with high gain and low profile for 60 $\mathrm{GHz}$ applications," in Proceedings of the IEEE MTT-S International Microwave Workshop Series on Advanced Materials and Processes for RF and THz Applications (IMWS-AMP), pp. 1-3, Pavia, Italy, 2016.

[17] K. Islam, T. Hossain, and M. M. Khan, "A compact novel design of a $60 \mathrm{GHz}$ antenna for body-centric communication," International Journal on Communications Antenna and Propagation (IRECAP), vol. 10, no. 5, pp. 325-333, 2020.

[18] K. Islam, T. Hossain, M. Monirujjaman Khan, M. Masud, and R. Alroobaea, "Comparative design and study of a $60 \mathrm{GHz}$ antenna for body-centric wireless communications," Computer Systems Science and Engineering, vol. 37, no. 1, pp. 19-32, 2021.

[19] A. R. Guraliuc, M. Zhadobov, G. Valerio, N. Chahat, and R. Sauleau, "Effect of textile on the propagation along the body at $60 \mathrm{GHz}$," IEEE Transactions on Antennas and Propagation, vol. 62, no. 3, pp. 1489-1494, 2014.

[20] A. R. Guraliuc, M. Zhadobov, G. Valerio, and R. Sauleau, "Enhancement of on-body propagation at $60 \mathrm{GHz}$ using electro textiles," IEEE Antennas and Wireless Propagation Letters, vol. 13, pp. 603-606, 2014.

[21] M. Monirujjaman Khan, K. Islam, M. N. A. Shovon, M. Masud, M. Baz, and M. A. AlZain, "Various textiles-based comparative analysis of a millimeter wave miniaturized novel antenna design for body-centric communications," International Journal of Antennas and Propagation, vol. 2021, Article ID 2360440, 14 pages, 2021.

[22] M. M. Khan, K. Islam, and N. A. Shovon, "Design of a novel $60 \mathrm{GHz}$ millimeter wave Q-slot antenna for body-centric communications," International Journal of Antennas and Propagation, vol. 2021, Article ID 9795959, 12 pages, 2021.

[23] Italian National Research Council, Dielectric Properties of Body Tissues in the Frequency Range $10 \mathrm{~Hz}$ to $100 \mathrm{GHz}$, Italian National Research Council, Rome, Italy, 2021, http://niremf. ifac.cnr.it/tissprop/.

[24] M. M. Khan, A. K. M. M. Alam, and P. Kumer, "Investigation of a compact ultra wideband Antenna for wearable applications," International Journal on Communications Antenna and Propagation, vol. 4, no. 4, pp. 124-129, 2014.

[25] M. M. Khan, Q. H. Abbasi, and R. H. Ashique, "Comprehensive design and propagation study of a compact dual band 
Antenna for healthcare applications," Journal of Sensor and Actuator Networks, Multidisciplinary Digital Publishing Institute, vol. 4, no. 2, pp. 50-66, 2015.

[26] M. M. Khan, Q. H. Abbasi, A. Alomainy, C. Parini, and Y. Hao, "Dual-band and dual-mode antenna for power-efficient body-centric wireless communications," in Proceedings of the IEEE International Symposium on Antennas and Propagation (APS), Spokane, WA, USA, July 2011.

[27] B. Y. Akowuah, E. T. Tchao, M. U. Rehman, M. M. Khan, and S. Ahmad, "Study of a printed split-ring monopole for dualspectrum communications," Heliyon, Elsevier.vol. 7, no. 9, Article ID E07928, 2021. 